\title{
Mineralogical study of the redeposited near-shore STD waste in Calancan causeway, Philippines
}

\author{
ROJA LABAY MEDIANISTA, ISMA IRSHAD, TAMÁS \\ GÁBOR WEISZBURG AND ERZSÉBET HARMAN-TÓTH
}

Eötvös Loránd University

Presenting Author: rlmmed31@gmail.com

Submarine tailings disposal (STD) has been a rather cheap mine waste technology. However, the disposal system causes environmental challenges due to unpredicted displacement of waste in more shallow areas. This causes changes in the physical and/or chemical composition of the mineral components as such as the case in Calancan causeway.

In the last 20 years, longshore drift redeposited a large portion of the northwest part of the Calancan causeway, forming a tombolo between the causeway and the near Banot Island. In the same time scale, the analysis of satellite images revealed the formation of patches of yellow precipitates expanding from $6 \mathrm{~m}^{2}$ to $1400 \mathrm{~m}^{2}$ area in the redeposited material which indicates an active oxidation process. This is possible since the causeway itself is formed from the waste disposal of porphyry copper deposits.

Our work focuses on the mineralogical analysis of the redeposited STD waste in Calancan causeway in relation to temporal and spatial data. Samples were collected at 3 different sites along the tombolo using pit sampling method.

Onsite observation of the sample profile and grain size distribution analysis in different sampling sites reveal variance in the distribution and sorting of the materials. Samples at the foreshore zone are stratified and sorted, while samples at the backshore remained homogenous. On the other hand, samples right after the berm crest have accumulation of 1-mm-thick yellow precipitate, followed by layers of oxidized and unoxidized zone. Based on laboratory analysis (stereomicroscopy, XRD, SEM+EDX, Raman spectroscopy) different alteration levels of the original sulphide minerals (pyrite, chalcopyrite) have been identified. The levels of alteration are limited in depth and vary with the location of the materials. Secondary minerals such as jarosite and iron oxyhydroxide (with some S content), copper carbonate(s) and chloride(s) with some clay minerals are found in different layers and at different sample locations. These ongoing progressive alteration processes are indicating the multifaceted fate of the displaced waste materials.

This work was completed in the ELTE Institutional Excellence Program (TKP2020-IKA-05), financed by the Hungarian Ministry of Human Capacities, and the participation of the first author was supported by the Koch Sándor Foundation. 